\title{
Regulation of osterix (Osx, Sp7) and the Osx promoter by parathyroid hormone in osteoblasts
}

\author{
Shara H H Hong, Xianghuai Lu ${ }^{1}$, Mark S Nanes ${ }^{1}$ and Jane Mitchell \\ Department of Pharmacology and Toxicology, University of Toronto, 1 King's College Circle, Room 4342, Toronto, Ontario, Canada M5S 1 A8 \\ ${ }^{1}$ Division of Endocrinology, Metabolism, and Lipids, Department of Medicine, Emory University School of Medicine and Veterans Affairs Medical Center, Atlanta, Georgia 30033, USA \\ (Correspondence should be addressed to J Mitchell; Email: jane.mitchell@ utoronto.ca)
}

\begin{abstract}
Parathyroid hormone $(\mathrm{PTH})$ binds to its receptor on osteoblasts to regulate gene transcription primarily through the elevation of the second messenger cAMP. A number of genes regulated by PTH in osteoblasts contain GC-rich and Sp-binding sites. Osterix (Osx, Sp7) is a transcription factor required for the differentiation of osteoblasts that can bind to Sp-binding sites on gene promoters and regulate their expression. Here, we report the effect of PTH (1-34) on Osx expression in osteoblastic UMR-106-01 cells and murine calvaria. PTH (1-34) and PTH (1-31) inhibited Osx mRNA and protein expression, and this effect could be mimicked by forskolin, 8-bromo-cAMP, or expression of constitutively active Gs $\alpha$ (caGs $\alpha$ ). Treatment of the cells with PTH (3-34) or the EPAC-selective agonist 8CPT-2Me-cAMP had no effect on Osx mRNA, whereas PTH (7-34) or expression of caGq $\alpha$-stimulated Osx mRNA levels. PTH (1-34) treatment did not require new protein synthesis and did not involve changes in Osx mRNA stability. Osx promoter fragments coupled to a luciferase reporter were inhibited by PTH (1-34) treatment in a similar manner to the inhibition of Osx mRNA and protein. Deletion analysis localized PTH inhibition to two regions flanking the Osx1 start site; $-304 /-119$ and $-71 /+91$. These results demonstrate that prolonged exposure to PTH inhibits Osx expression in osteoblasts through sites on its proximal promoter and this suppression occurs through PTH stimulation of cellular cAMP.
\end{abstract}

Journal of Molecular Endocrinology (2009) 43, 197-207

\section{Introduction}

Osterix (Osx, Sp7) is a zinc finger-containing transcription factor belonging to the Sp subgroup of the Krüppel-like family. It was first identified as a bone morphogenic protein-2 (BMP-2)-induced gene in osteoprogenitor cells (Nakashima et al. 2002). The mouse Osx homolog is a 428 amino acid polypeptide with a molecular mass of $\sim 45 \mathrm{kDa}$. More recently, three alternatively spliced variants of the murine Osx mRNA have been identified by $5^{\prime}$ RACE experiments (Nishio et al. 2006), with the most abundant isoform being the transcript originally reported by Nakashima et al. (2002). In humans, two isoforms have been identified and named as $\operatorname{Sp} 7-\alpha$ and $-\beta$ isoforms, sharing $95 \%$ sequence homology with murine Osx (Milona et al. 2003, Gao et al. 2004).

Osx is expressed specifically in osteoblasts and transiently in differentiating chondrocytes (Nakashima et al. 2002). Osx null mice lack bone formation with a phenotype similar to that of runt-related transcription factor 2 (Runx2, also known as core-binding factor- $\alpha 1$ (Cbfa1)) null mice (Komori et al. 1997). In both Runx2and Osx-deficient mice, osteoblast differentiation is arrested and expression of a number of osteoblast markers, osteonectin, osteopontin, osteocalcin, and bone sialoprotein is absent (Komori et al. 1997, Nakashima et al. 2002). Runx2 null mice do express Osx while Osx null mice lack Runx2 expression, suggesting that Osx is either acting downstream of Runx2 or expressed later in the osteoblast differentiation pathway.

Functional roles for Osx in bone and cartilage have only recently been investigated. Osx is thought to regulate transcription of many osteoblast marker genes containing GC-rich and Sp-binding sites on their promoters. Forced expression of Osx in vitro has been reported to induce expression of osteocalcin and collagen type 1A1 (Nakashima et al. 2002), collagen type 11A2 (Goto et al. 2006), and osteopontin (Kim et al. 2006). Osx may also inhibit osteoblast proliferation through the inhibition of the Wntsignaling pathway (Zhang et al. 2008) and act as a negative regulator of chondrogenesis (Tominaga et al. 2009). Osx expression has also been suggested to play a role in tumor growth and metastasis, and osteolytic activity of tumor cells may be regulated by Osx via down-regulation of interleukin- $1 \alpha$ gene transcription (Cao et al. 2008). Therefore, understanding the regulation of Osx gene expression could be beneficial in modulating the osteoblast differentiation, bone formation, and tumor activity.

DOI: 10.1677/JME-09-0012 Online version via http://www.endocrinology-journals.org 
Several factors that can modulate Osx expression have been identified. Both BMP-2 and insulin-like growth factor-1 (IGF-1) can induce Osx expression in undifferentiated mesenchymal stem cells through Runx2-dependent (Celil \& Campbell 2005) and Runx2-independent (Lee et al. 2003) pathways. Ascorbic acid and 1,25 $(\mathrm{OH})_{2}$ vitamin $\mathrm{D}_{3}$, which have positive roles in osteoblast function, have also been shown to up-regulate Osx expression (Maehata et al. 2006, Xing et al. 2007). Negative regulators of osteoblastogenesis, such as tumor necrosis factor- $\alpha$ $(\mathrm{TNF}-\alpha)$ and p53, can inhibit Osx expression ( $\mathrm{Lu}$ et al. 2006, Wang et al. 2006a,b, Zambetti et al. 2006).

Parathyroid hormone (PTH) is known to have both anabolic and catabolic effects on bone depending on the duration of exposure (Frolik et al. 2003). Many osteoblast marker genes including type I collagen (Kream et al. 1980), osteopontin (Noda \& Rodan 1989), osteonectin (Termine et al. 1981), and osteoprotegerin (Lee \& Lorenzo 1999) are regulated by PTH. Some gene regulation by PTH may be mediated by PTH stimulation of the activity of the skeletal-specific transcription factor Runx2 (Ducy et al. 1997). The best characterized role of PTH stimulation of Runx2 is the stimulation of matrix metalloproteinase-13 (MMP-13) in UMR-106-01 and other osteoblast cell lines (Selvamurugan et al. 2000). The aim of this study was to examine whether PTH regulated Osx in osteoblasts and whether this was downstream of Runx2 activation.

\section{Materials and methods}

\section{Materials}

Rat PTH (1-34), human PTH (1-31), bovine PTH (3-34), and bovine (D-Trp ${ }^{12}$ and $\mathrm{Tyr}^{34}$ ) PTH (7-34) amide were purchased from Bachem Bioscience, Inc. (King of Prussia, PA, USA). H89, 8-bromo-cAMP (8-BrcAMP), forskolin (Fsk), and 5,6-dichlorobenzimidazole riboside (DRB) were purchased from EMD Biosciences, Inc. (San Diego, CA, USA). Cycloheximide (CHX) was purchased from Sigma. 8CPT-2Me-cAMP was purchased from Cedarlane Laboratories (Burlington, Ontario, Canada). cDNAs encoding constitutively active Gs $\alpha$ (caGs $\alpha$; Q227L) and $c^{2 a G q \alpha}(\mathrm{Q} 209 \mathrm{~L})$ were purchased from Missouri S\&T cDNA Resource Center (University of Missouri at Rolla, Rolla, MO, USA).

\section{Cell culture and mouse calvaria preparation}

UMR-106-01 osteosarcoma cells (UMR; a gift from Dr N Partridge, UMDNJ-Robert Wood Johnson Medical School, Piscataway, NJ, USA) were grown as previously described (Erclik \& Mitchell 2002). CD1 mice with timed pregnancy were purchased from Charles River Laboratories (St Constant, Quebec, Canada). Animals were treated according to the guidelines of the University of Toronto animal care committee. Frontal and parietal sections of calvaria were dissected from E18.5 and PN4-5 mice. Periosteal membranes were removed and calvaria were hemisected. Calvaria were cultured in DMEM (high glucose) containing antibiotic-antimycotic and $10 \%$ fetal bovine serum with two randomly selected calvaria halves/well in 24-well culture plates containing $1 \mathrm{ml}$ of medium/well.

\section{Cell treatment and RNA extraction}

UMR cells were plated at a density of $5 \cdot 4 \times 10^{5}$ cells $/$ well in six-well plates on day 1 and treated with PTH on day 2 and day 3 for up to $24 \mathrm{~h}$. On day 3 , total RNA was extracted using TRIzol (Gibco BRL, Life Technologies) according to the manufacturer's instructions. For experiments using CHX, DRB, or signaling activators, the same protocol was followed as for PTH. In experiments using signaling inhibitors, cells were pretreated with specific inhibitors for $30 \mathrm{~min}$ before the addition of PTH. For calvaria, four halves of calvaria were collected in $1 \mathrm{ml}$ of TRIzol and homogenized in a dounce tissue homogenizer (Wheaton, Millville, NJ, USA) before RNA extraction.

UMR cell lines expressing Gs $\alpha$ (Q227L) or Gq $\alpha$ (Q209L) or a control vector expressing green fluorescent protein (GFP) were generated by transfection of cDNAs in pcDNA3.1 vectors using Lipofectamine (Life Technologies). Two days after transfection, transfected cells were selected by incubating the cells in medium containing $400 \mu \mathrm{g} / \mathrm{ml}$ G418 (Sigma) for 7 days. Cells were subcultured into media containing G418 and grown for 3 days prior to RNA extraction as outlined above.

\section{Real-time PCR}

Before reverse transcriptase (RT) reaction, $1 \mu \mathrm{g}$ of total RNA was digested with $1 \mathrm{U}$ of DNase I (Fermentas, Burlington, Ontario, Canada) to remove any contaminating genomic DNA. Each RNA sample was then reverse transcribed using $200 \mathrm{U}$ of MMLV reverse transcriptase (Invitrogen) in a total volume of $20 \mu \mathrm{l}$ with standard RT procedure. The RT products were amplified by real-time PCR amplification using a 7500 Real-time PCR System (Applied Biosystems, Foster City, CA, USA). For each reaction, $0 \cdot 8 \mu$ of the RT product of calvaria samples or $0 \cdot 3 \mu \mathrm{l}$ of RT product of UMR samples was amplified in a cocktail containing Power SYBR Green PCR Master Mix (Applied Biosystems), $0.3 \mathrm{mM}$ forward and reverse primers in sterile distilled water in a total volume of $20 \mu \mathrm{l}$ using standard cycling conditions $\left(50^{\circ} \mathrm{C}\right.$ for $2 \mathrm{~min}, 95^{\circ} \mathrm{C}$ for $10 \mathrm{~min}, 40$ cycles 
of $95^{\circ} \mathrm{C}$ for $15 \mathrm{~s}$, and $60{ }^{\circ} \mathrm{C}$ for $1 \mathrm{~min}$ ). Primers for amplifying mouse and rat Osx, Runx2, and glyceraldehyde-3-phosphate dehydrogenase (GAPDH) were designed using the Primer express software (v.3; Applied Biosystems). The primers used were: rat Osx forward: $5^{\prime}$ CAG CCT GCA GCA AGT TTG G 3'; reverse: $5^{\prime}$ TTT TCG CAG GGC TGT TGA GT $3^{\prime}$; mouse Osx forward: $5^{\prime}$ GGT CCC CAG CTC GAG GAT $3^{\prime}$; reverse: $5^{\prime}$ CTA GAG CCG CCA AAT TTG CT $3^{\prime}$; rat Runx2 forward: $5^{\prime}$ CAG GTT CAA CGA TCT GAG ATT TGT $3^{\prime}$; reverse: $5^{\prime}$ TGA AGA CCG TTA TGG TCA AAG TGA $3^{\prime}$; mouse Runx2 forward $5^{\prime}$ ACT GGC GGT GCA ACA AGA C $3^{\prime}$; reverse: $5^{\prime}$ ACC ACA GTC CCA TCT GGT ACC T $3^{\prime}$; GAPDH forward: $5^{\prime}$ CAT GGC CTT CCG TGT TCC TA 3'; reverse: 5' GCG GCA CGT CAG ATC CA $3^{\prime}$. GAPDH was used as an internal control for the quality and quantity of the cDNA products as well as a normalization standard for relative quantification analysis. All real-time PCR results were analyzed by relative quantification $\left(\mathrm{RQ}=2^{-\Delta \Delta C_{\mathrm{t}}}\right)$ calculation, where $C_{\mathrm{t}}$ is the cycle number required to reach the threshold minus the cycle number of the baseline.

\section{Protein extraction and western blotting}

UMR cells were plated at a density of $5 \cdot 4 \times 10^{5}$ cells/well in six-well plates on day 1 and treated with PTH on day 2 and day 3. On day 3, cells were extracted in a buffer containing $50 \mathrm{mM}$ Tris $\mathrm{pH} 7 \cdot 5,16 \mathrm{mM}$ EDTA, $1 \mathrm{mM}$ dithiothreitol, $2 \mathrm{mM}$ 4-(2-aminoethyl)-benzenesulfonyl fluoride hydrochloride (AEBSF), $1 \mathrm{mM}$ sodium fluoride, $1.5 \mathrm{mM}$ sodium orthovanadate, $1 \% \mathrm{NP} 40$, $0.2 \%$ deoxycholate, and $10 \mu \mathrm{g} / \mathrm{ml}$ trypsin inhibitor as previously described (Lai et al. 2005). Protein samples were separated by electrophoresis on $11 \%$ SDSpolyacrylamide gels, transferred to nitrocellulose membranes overnight at $4{ }^{\circ} \mathrm{C}$, and blocked with $5 \%$ milk, $0 \cdot 1 \%$ Tween, Tris-based buffer (TBST) for $2 \mathrm{~h}$. To determine specific protein expression, nitrocellulose membranes were probed with specific antibodies diluted in TBST containing $1 \%$ BSA overnight at $4{ }^{\circ} \mathrm{C}$. To determine Osx protein expression, nitrocellulose membranes were probed with Osx polyclonal antibody (Abcam, Cambridge, MA, USA) diluted (1:500) in TBST containing $1 \%$ BSA overnight at $4{ }^{\circ} \mathrm{C}$ and probed with HRP-conjugated anti-rabbit IgG antibody (GE Healthcare, Baie d'Urfe, Quebec, Canada) diluted $(1: 10000)$ in TBST with $5 \%$ milk for $1 \mathrm{~h}$. To determine Erk1/2 protein expression, nitrocellulose membranes were probed with polyclonal Erk1/2 antibody (Cell Signaling Technology, Danvers, MA, USA) diluted (1:1000) and probed with HRP-conjugated anti-rabbit IgG antibody (Cell Signaling Technology) diluted (1:5000) with the same conditions. Nitrocellulose membranes were then incubated with ECL-enhanced chemiluminesence solution (GE Healthcare) and exposed to X-ray films. Protein bands were quantitated by densitometry using ImageQuant software (Molecular Dynamics, Sunnyvale, CA, USA).

\section{Reporter constructs and luciferase assays}

The Runx2 reporter plasmid containing six copies of the Runx2-binding site (OSE2) in a p4Luc promoterless luciferase expression plasmid (Ducy \& Karsenty 1995) was used to assess Runx2 activity. The Osx promoter plasmid $\left(\mathrm{pGL}_{3}-1269 /+91 \mathrm{bp}\right)$ containing $5^{\prime}$-flanking region $-1269 \mathrm{bp}$ upstream from the initiation methionine start site to $+91 \mathrm{bp}$ of downstream sequence attached to a $\mathrm{pGL}_{3}$-basic luciferase reporter plasmid (Promega) and deletion constructs have been previously described (Lu et al. 2006). Mutation construct $\mathrm{pGL}_{3}-1269 /+91$ (m214/217), deletion construct $\mathrm{pGL}_{3}-1269 /+91(\Delta \mathrm{NF} \kappa \mathrm{B})$, and a plasmid containing four repeats of NFKB-binding site $(-228 /-208$ bp Osx promoter sequence) attached to the promoter SV40-luciferase pGL-promoter (pGL$\mathrm{NF} \kappa \mathrm{B} \times 4)$ were also previously described ( $\mathrm{Lu}$ et al. 2006). For luciferase assays, UMR cells were plated at a density of $10^{5}$ cells/well in 24-well plates on day 1 . Transfections were performed on day 2 using lipofectamine (Invitrogen). About $0 \cdot 2 \mu \mathrm{g}$ of reporter constructs and $0 \cdot 2 \mu \mathrm{g}$ of pSV- $\beta$-gal cDNA were transfected with $3 \mu \mathrm{l}$ of lipofectamine in DMEM:F12 serum-free, antibioticantimycotic-free medium for $6 \mathrm{~h}$. pSV- $\beta$-gal, a betagalactosidase $(\beta$-gal) expression plasmid under the control of a simian virus 40 promoter (Promega), was used to correct for transfection efficiency between wells. After transfection, cell media were replaced with fresh DMEM:F12 medium containing 5\% serum and antibiotic-antimycotic. On day 3, cells were treated with PTH for up to $24 \mathrm{~h}$, and then lysed with $100 \mu \mathrm{l}$ cell lysis buffer/well (Promega). Luciferase activity was assessed using a commercial kit (Promega). All luciferase results were corrected for transfection efficiency using $\beta$-gal activity. In a subset of experiments, UMR cells were plated at a density of $10^{6}$ cells/well in $100 \mathrm{~mm}$ plates on day 1 . On day 2, pFLAG- $\mathrm{cmv}_{2}-\mathrm{Sp} 7$, an Osx expression plasmid containing a full-length cDNA for the mouse Sp7/Osx and N-terminal FLAG epitope tag, and p-cmv 2 obtained from Toshihisa Komori (Division of Oral Cytology and Cell Biology, Department of Developmental and Reconstructive Medicine, Nagasaka University Graduate School of Biomedical Sciences, Nagasaki, Japan; Goto et al. 2006) were transfected with a 1:4 ratio of DNA to lipofectamine 2000 in DMEM:F12 serum-free, antibiotic-antimycotic-free medium for $5 \mathrm{~h}$ followed by a change of medium to fresh DMEM:F12 medium containing 5\% serum and antibiotic-antimycotic. On day 3 , proteins were extracted and immunoblotted for Osx expression. 


\section{Data presentation and statistical analysis}

Data from at least three independent experiments were expressed with error bars indicating \pm s.E.M. All statistical analyses were performed with GraphPad Prism software (San Diego, CA, USA). One-way ANOVA, where $P<0.05$ was considered statistically significant, was used to determine the effect of treatment on gene expression and protein expression followed by Bonferroni post hoc analysis. Unpaired $t$-tests were performed to determine the effect of PTH on Osx mRNA stability and the effect of PTH on reporter constructs in luciferase assays.

\section{Results}

\section{PTH suppresses Osx mRNA levels}

To study the effect of PTH on Osx mRNA levels, UMR cells were treated with increasing concentrations of PTH (1-34) for $3 \mathrm{~h}$. As shown in Fig. 1A, PTH (1-34) inhibits Osx mRNA in a concentration-dependent manner. Treatment of UMR cells with $10 \mathrm{nM} \mathrm{PTH}$ (1-34) has been reported to strongly activate PTH1R
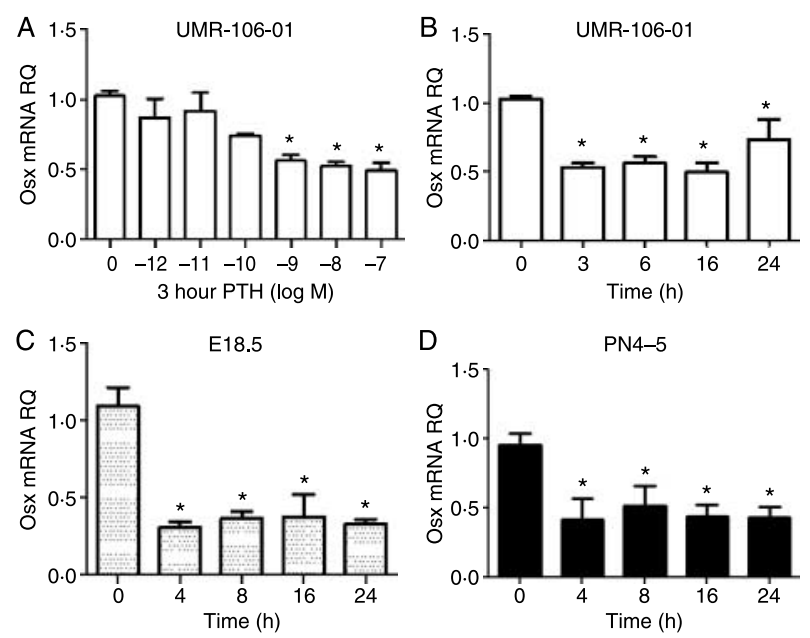

Figure $1 \mathrm{PTH}$ regulation of Osx mRNA in osteoblasts. UMR106-01 cells, E18.5, and PN4-5 calvaria were treated with PTH (1-34) for various times before quantification of Osx mRNA levels by relative real-time PCR standardized with GAPDH. (A) UMR106-01 cells were stimulated with the indicated concentrations of PTH (1-34) for $3 \mathrm{~h}$. PTH (1-34) significantly inhibited Osx mRNA levels at concentrations of $1 \mathrm{nM}$ or higher. (B) Time course of PTH (1-34; $10 \mathrm{nM}$ ) stimulation showed that Osx was inhibited between 3 and $24 \mathrm{~h}$ of PTH treatment. Similar PTH-mediated suppression of Osx mRNA levels was observed in calvaria extracted from E18.5 (C) and PN4-5 (D) mice treated with $100 \mathrm{nM} \mathrm{PTH} \mathrm{(1-34)}$ for the indicated time periods. Average Osx mRNA levels obtained from at least three independent experiments were plotted with error bars representing mean \pm S.E.M. Statistical significance was represented by ${ }^{\star} P<0.05$, compared with cells incubated with $\mathrm{PTH}$-free medium. signal transduction pathways to regulate a number of genes involved in bone formation and bone degradation (Erclik \& Mitchell 2002, Qin et al. 2003). Treatment of UMR cells with this concentration inhibited Osx mRNA level by $27-47 \%$ over a time course of 3-24 h (Fig. 1B). To determine whether PTH had similar effects on primary mouse osteoblasts, calvaria were dissected from mice at either E18.5 or PN4-5 and cultured with $100 \mathrm{nM}$ PTH (1-34) for various times. Higher concentrations of PTH were used with the calvaria, as primary osteoblasts have previously been shown by others to have lower PTH1R receptor density than UMR cells (Forrest et al. 1985, Bos et al. 1996). In calvaria where bone matrix was intact and other cell types were present, 4-24 $\mathrm{h}$ exposure to $100 \mathrm{nM}$ PTH (1-34) significantly suppressed Osx mRNA levels indicating consistency with the effect observed in UMR cells (Fig. 1C and D). Over the time course examined PTH (1-34) treatment suppressed Osx mRNA levels by $70-62 \%$ in E18.5 and $59-49 \%$ in PN4-5 calvaria.

\section{PTH down-regulates Osx protein}

Western blotting was performed to investigate whether the effect of PTH (1-34) on Osx mRNA resulted in a change of Osx protein level. Osx was expressed as two isoforms in the UMR cells where the identity of Osx protein isoforms was confirmed with transient transfection of exogenous Osx expression plasmid (Fig. 2C). A $46 \mathrm{kDa}$ Osx protein originally reported by Nakashima et al. (2002) was detected by the Osx polyclonal antibody (Fig. 2A), and an additional, higher molecular mass of $56 \mathrm{kDa}$ form was also detected and appeared to be regulated by PTH in the same manner (Fig. 2A). In UMR cells, Osx protein levels were significantly suppressed after $6-24 \mathrm{~h}$ of $10 \mathrm{nM}$ PTH (1-34) treatment with maximal $74 \pm 7 \%$ suppression seen after $24 \mathrm{~h}$ (Fig. 2B). Thus, our experiments indicated that both Osx mRNA and protein are regulated by PTH (1-34) in osteoblasts with the change in mRNA preceding the change in protein level.

\section{PTH inhibition of Osx is not mediated by Runx2}

Runx2 is a transcription factor in osteoblasts whose expression has been shown to precede Osx expression during osteoblastic differentiation. Since Runx2 has been shown to stimulate Osx expression in osteoblasts and PTH has been shown to regulate Runx2, we examined whether the loss of Runx2 could mediate the inhibitory effect of PTH on Osx. In the UMR cells, PTH (1-34) treatments from 3 to $24 \mathrm{~h}$ had no effect on Runx2 mRNA levels in UMR cells (Fig. 3A). However, PTH (1-34) could stimulate Runx2 activity 

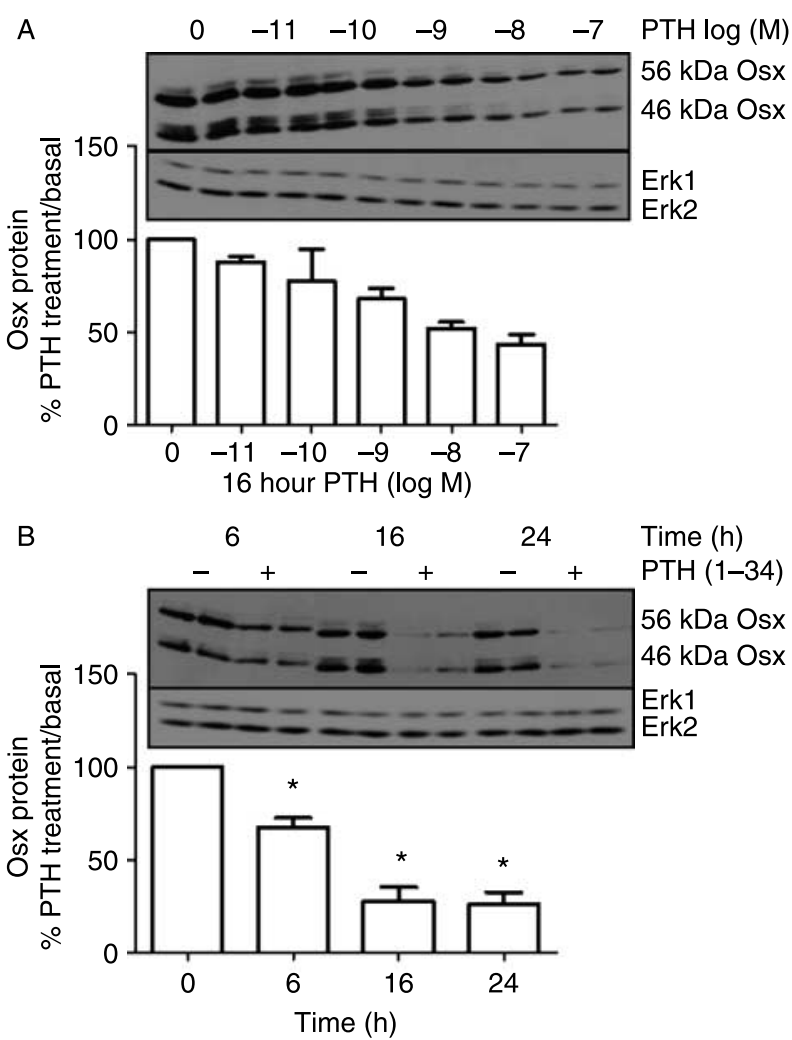

C

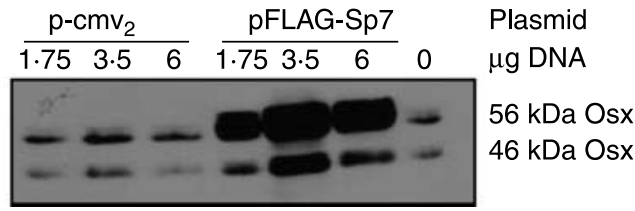

Figure 2 PTH regulation of Osx proteins in UMR-106-01. UMR cells were treated with PTH (1-34) for the indicated time periods before protein extraction. Total cell lysates $(25 \mu \mathrm{g})$ were separated by SDS-PAGE, blotted into nitrocellulose, and probed with specific polyclonal Osx antibody. Two isoforms of Osx were suppressed by PTH (1-34) in a concentration-dependent (A) and time-dependent (B) manner. The $45 \mathrm{kDa}$ Osx was quantified from at least three blots where the averages were plotted with error bars representing mean \pm S.E.M. Statistical significance was represented by ${ }^{\star} P<0.05$, compared with cells incubated with PTH-free medium. (C) UMR-106-01 cells were transfected with the indicated amounts of cDNA encoding pFLAG-Sp7 or control p-cmv2 vector before protein extraction. Total cell lysates $(25 \mu \mathrm{g})$ were separated by SDS-PAGE, transferred onto nitrocellulose, and probed with Osx-specific antibody.

as demonstrated by a construct containing six OSE2 Runx2-binding elements fused to luciferase (Fig. 3B). The use of the cAMP analog 8-Br-cAMP and the adenylyl cyclase activator Fsk showed that PTHstimulated Runx2 activity via a cAMP pathway (Fig. 3B), which is consistent with previous reports by others (Selvamurugan et al. 2000). PTH (1-34) also had no significant effect on Runx2 mRNA levels in calvaria harvested from either E18.5 or PN4-5 mice (Fig. 3C and D).

\section{Involvement of cAMP in PTH-mediated effect on Osx}

To investigate the signaling pathway involved in PTHmediated suppression of Osx, several PTH analogs and selective signaling activators were utilized. PTH (1-31), which induces cAMP as strongly as PTH (1-34) (Jouishomme et al. 1994), also inhibited Osx expression (Fig. 4A). PTH (3-34), which does not induce cAMP (Erclik \& Mitchell 2002), had no effect (Fig. 4A), whereas PTH (7-34), which does not activate PTH1R, can act as an antagonist stimulated Osx expression (Fig. 4A).

8-Br-cAMP and Fsk treatments mimicked the effect of PTH in suppressing Osx mRNA levels, suggesting a cAMP-dependent pathway (Fig. 4B). Addition of RpcAMP, a competitive PKA inhibitor, was able to partially abrogate PTH (1-34) inhibition of Osx mRNA, whereas 8CPT-2Me-cAMP, a selective stimulator of EPAC (Kang et al. 2003), had no effect on Osx mRNA levels. Furthermore, UMR cells expressing caGs $\alpha$ had $\sim 50 \%$ of the Osx mRNA levels found in cells expressing a GFP control (Fig. 4C). Interestingly, those cells expressing caGq $\alpha$ expressed significantly more Osx than the control cells (Fig. 4C). Together, these data suggest that PTH inhibits Osx expression through activation of Gs $\alpha$ and stimulation of adenylyl cyclase, and that the weak regulation of phospholipase $\mathrm{C}$
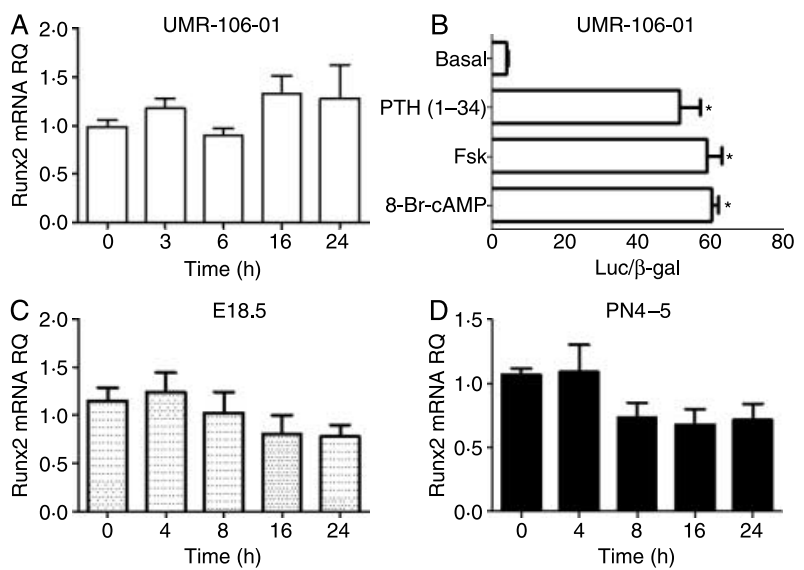

Figure 3 PTH regulation of Runx2 in osteoblasts. UMR-106-01 cells and calvaria (E18.5 and PN4-5) were treated with 10 and $100 \mathrm{nM}$ of PTH (1-34) respectively for the indicated time periods before RNA extraction. Osx mRNA levels were quantified by relative real-time PCR standardized with GAPDH. Time course of PTH showed no effect on Runx2 mRNA levels in UMR-106-01 cells (A) and calvaria extracted from E18.5 (C) and PN4-5 (D) mice. To study Runx2 activity, UMR-106-01 cells were transiently transfected with OSE2 reporter and treated with $10 \mathrm{nM} \mathrm{PTH}$ (1-34) or signaling mediators ( $10 \mu \mathrm{M}$ Fsk and $1 \mathrm{mM} 8-\mathrm{Br}-\mathrm{cAMP})$ for $6 \mathrm{~h}$ (B). Average Runx2 mRNA levels and luciferase activities standardized with $\beta$-gal activities from at least three independent experiments were plotted with error bars representing mean \pm S.E.M. Statistical significance was represented by ${ }^{*} P<0.05$ compared with cells incubated with PTH-free medium. 

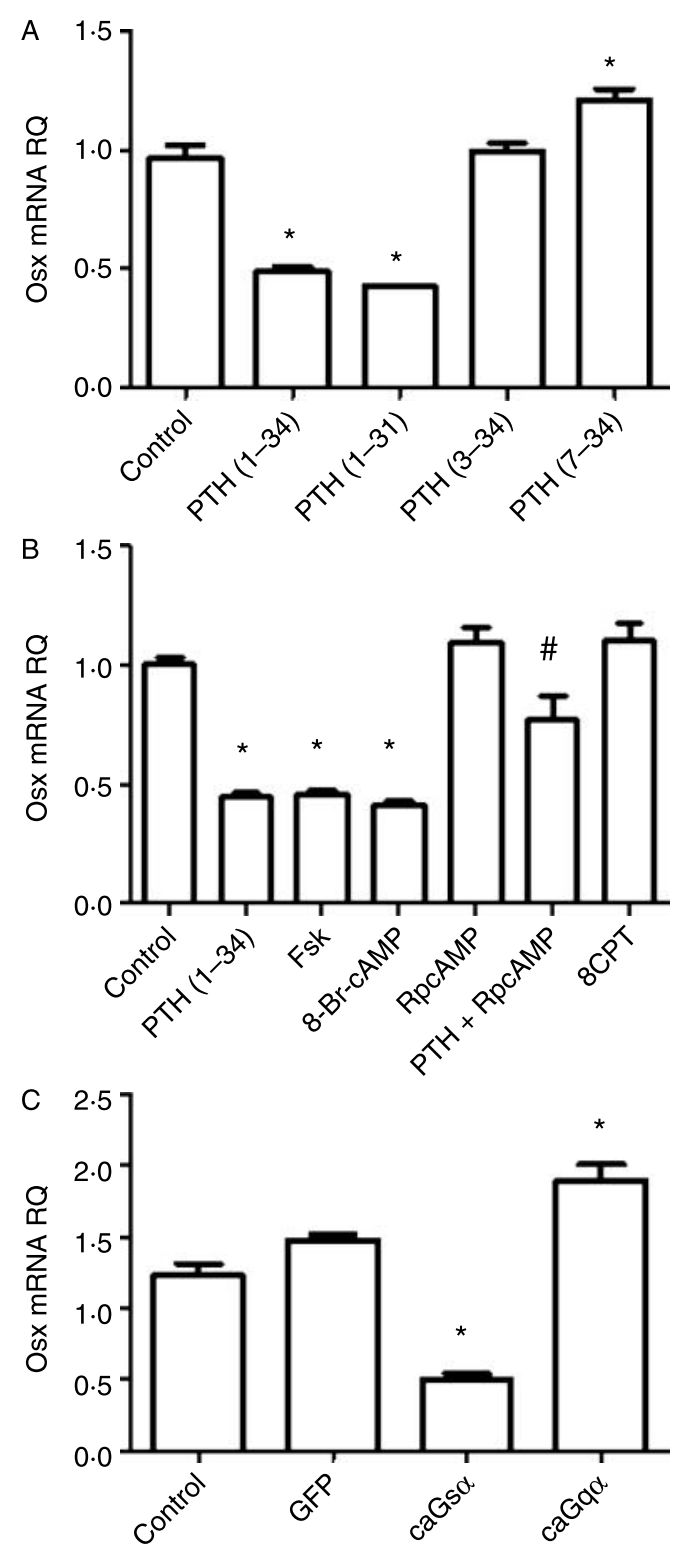

Figure 4 PTH regulates Osx through a cAMP-dependent pathway. (A) UMR-106-01 cells were treated with PTH analogs (10 nM (1-34), $10 \mathrm{nM}(1-31), 100 \mathrm{nM}$ (3-34), and $100 \mathrm{nM}(7-34)$ ) for $3 \mathrm{~h}$ before RNA extraction. (B) UMR-106-01 cells were treated with $10 \mathrm{nM}$ of PTH (1-34) or with cAMP-signaling mediators of $10 \mu \mathrm{M}$ forskolin (Fsk), $1 \mathrm{mM}$ 8-Br-cAMP, $10 \mu \mathrm{M}$ RpcAMP, and $50 \mu \mathrm{M}$ 8CPT-2Me-cAMP (8CPT) for $3 \mathrm{~h}$ before RNA extraction. (C) UMR-106-01 cells were transfected with GFP, constitutively active Gs $\alpha$ (Q227L; caGs $\alpha$ ), or constitutively active Gq $\alpha$ (Q209L; caGq $\alpha$ ) and transfectants were selected in medium containing G418 for 4 days prior to RNA extraction. Osx mRNA levels were quantified by relative real-time PCR standardized with GAPDH. Average Osx mRNA levels obtained from at least three independent experiments were plotted with error bars representing mean \pm S.E.M. Statistical significance was represented by ${ }^{*} P<0.05$, compared with cells incubated with PTH-free medium. ${ }^{\#}$ Represents statistical significance compared with cells incubated with PTH (1-34) alone, $P<0.05$.
(PLC) by PTH in these cells (Mitchell \& Bansal 1997, Cheung et al. 2005) is not likely to contribute to this inhibition.

\section{PTH-mediated suppression of Osx does not require protein synthesis and is not mediated by changing Osx mRNA stability}

The protein synthesis inhibitor CHX was used to determine whether de novo protein synthesis was required for the effect of PTH (1-34) on Osx. Three hours of CHX treatment alone did not significantly change the Osx mRNA levels (Fig. 5A). Co-treatment of CHX and PTH (1-34) significantly suppressed Osx mRNA levels, suggesting that de novo protein synthesis was not required for PTH-mediated Osx suppression (Fig. 5A). To determine the effect of PTH (1-34) on Osx mRNA stability, UMR cells were treated with the RNA polymerase II inhibitor, DRB. In the absence of PTH (1-34), Osx mRNA half-life was $0.55 \mathrm{~h}$; while in the presence of PTH (1-34) this was $0.74 \mathrm{~h}$, which was not significantly different, indicating that PTH treatment did not inhibit Osx mRNA levels by decreasing its stability (Fig. 5B).

\section{PTH regulates Osx transcription}

We next examined whether PTH regulated Osx transcription using an Osx promoter coupled to luciferase in reporter assays. As shown in Fig. 6A, PTH (1-34) significantly suppressed the activity of the -1269 bp Osx promoter construct in a time-dependent manner, which was similar to the effects seen on Osx mRNA. To localize PTH-responsive region(s), Osx promoter fragments with serial deletions from the $5^{\prime}$ end were used. After truncation of the promoter, about half of the PTH-inhibitory effect on Osx promoter activity was localized to $-304 /-119$ and the remaining inhibitory effect to the more proximal promoter between -71 and +91 (Fig. $6 \mathrm{~B}$ ). It is possible that a protein-DNA interaction involving more than one discrete promoter region confers $\mathrm{PTH}$ inhibition. The -304 to $-119 \mathrm{bp}$ sequence contained a putative binding site for $\mathrm{NF \kappa B}$, and so we examined whether this NFKB could mediate part of the PTH inhibition of the Osx promoter. A reporter construct containing four NFКB-binding sites was significantly stimulated by PTH (1-34), indicating that PTH (1-34) stimulated, rather than suppressed, NFKB activity in the UMR cells (Fig. 6C). However, this stimulation of $\mathrm{NF \kappa B}$ activity had no effect on Osx expression since promoter activity of the full-length $-1269 /+91$ Osx promoter with the $\mathrm{NF} \kappa \mathrm{B}$-binding site sequence deleted $(\triangle \mathrm{NF} \kappa \mathrm{B})$ or mutated (m217/214) was suppressed by PTH (1-34) treatment (Fig. 6C). 

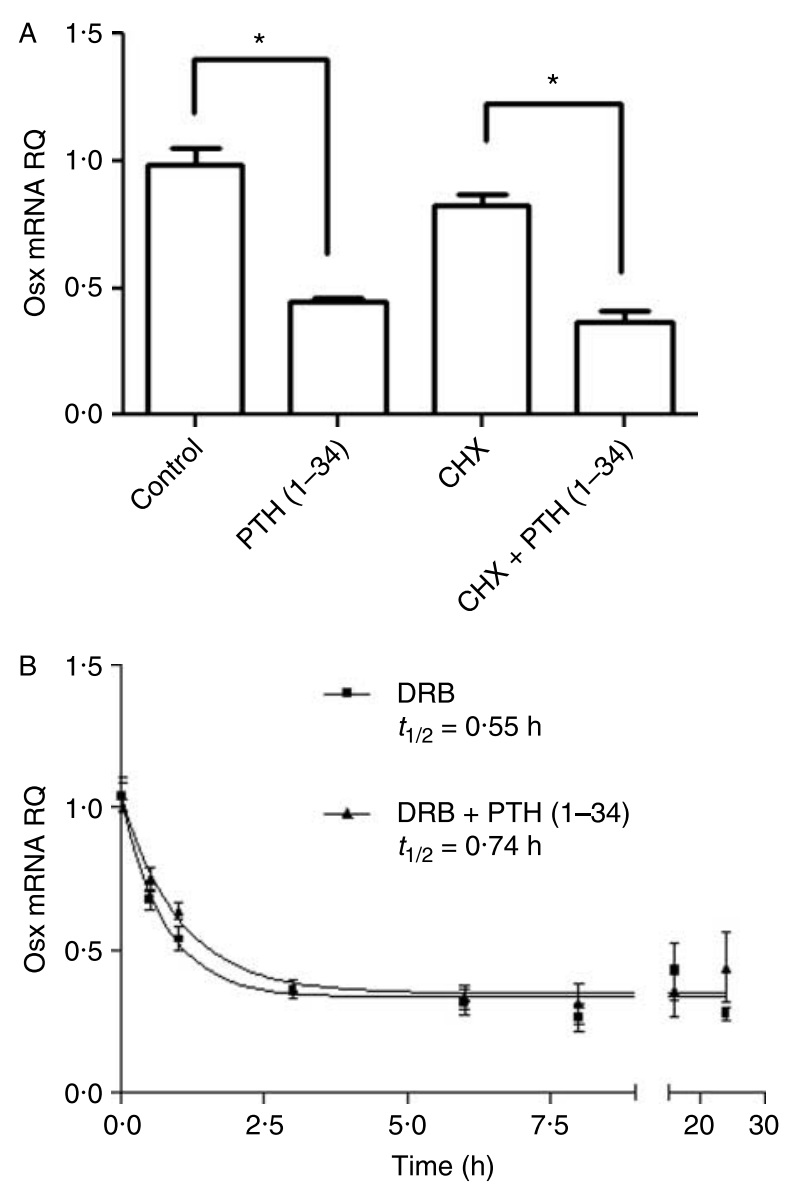

Figure $5 \mathrm{PTH}$ regulation of Osx is independent of de novo protein synthesis and Osx mRNA stability. UMR-106-01 cells were treated with $10 \mathrm{nM}$ PTH (1-34) and/or $1 \mu \mathrm{M}$ cycloheximide (CHX) for $3 \mathrm{~h}(\mathrm{~A})$. Cells were treated with DRB $(50 \mu \mathrm{g} / \mathrm{ml})$ or co-treated with PTH $(1-34 ; 10 \mathrm{nM})$ for the indicated time periods to measure the half-life of Osx mRNA (B). Osx mRNA levels were quantified by relative real-time PCR standardized with GAPDH. Average Osx mRNA levels obtained from at least three independent experiments were plotted with error bars representing mean \pm S.E.M. Statistical significance were represented by ${ }^{\star} P<0.05$, compared with cells incubated with PTH-free medium.

\section{Discussion}

Our results demonstrate that $\mathrm{PTH}$ is a major regulator of Osx expression in osteoblasts. Significant suppression of Osx mRNA was seen within 3-4 h of PTH (1-34) application to the UMR cells or calvaria, and this was quickly followed by detectable loss of Osx protein. The suppression of both mRNA and protein was sustained over a 24-h period, and Osx proteins were barely detectable during the last $8 \mathrm{~h}$ of this treatment. Our results agree with previous studies in which the PTHrelated peptide, PTHrP (1-34), which also interacts with the PTH1R, caused inhibition of Osx mRNA in differentiated KS483 cells with a similar time course to that seen in our study (van der Horst et al. 2005).
Our studies disagree with a previous report by Wang et al. $(2006 a, b)$ in which they demonstrated that a low concentration of PTH (1-34)-stimulated Runx2 and Osx mRNA levels in UMR-106 cells. Their results are clearly different from ours as well as studies from the Partridge laboratory which showed that PTH did not increase Runx2 mRNA or protein, but rather activates Runx2 by PKA-mediated phosphorylation (Selvamurugan et al. 2000, 2009). It is possible that
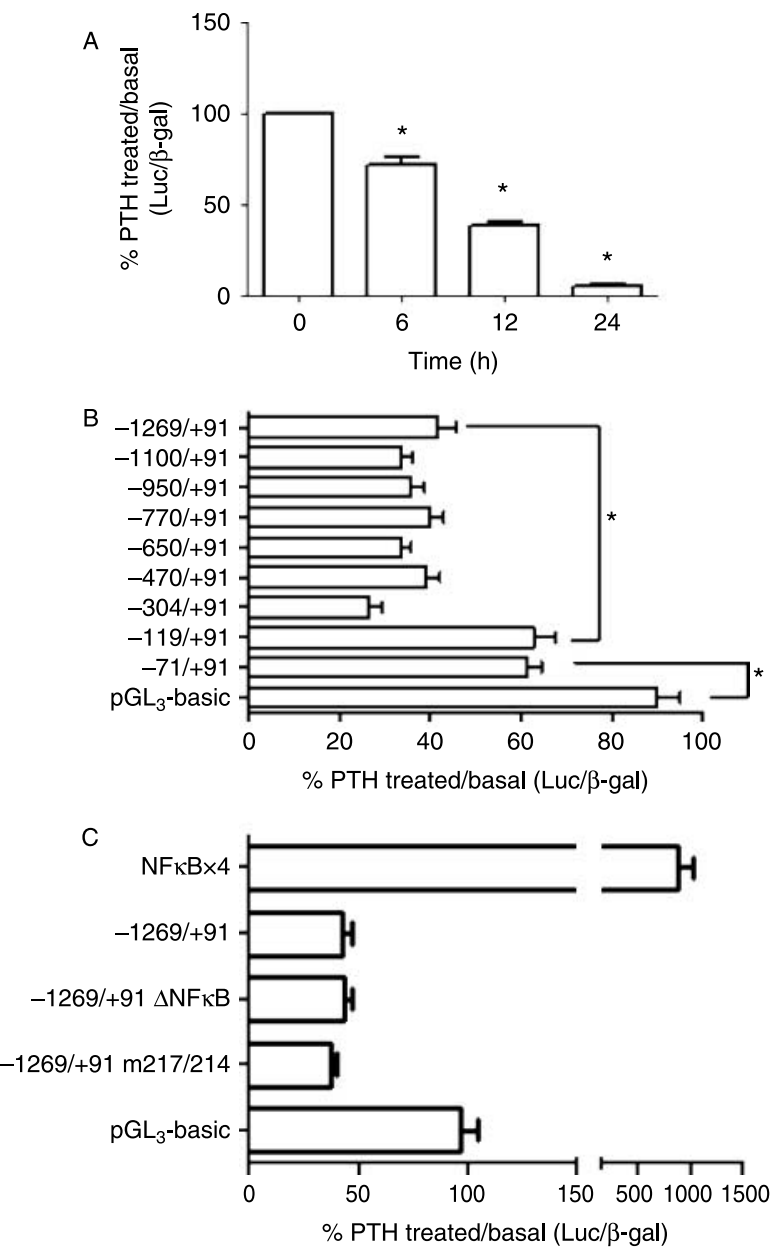

Figure 6 PTH regulation of Osx promoter. UMR-106-01 cells were transiently transfected with the $-1269 /+91$ Osx promoter reporter and treated with $10 \mathrm{nM}$ of PTH (1-34) for the indicated time periods (A). To localize PTH-response region(s), cells were transiently transfected with Osx promoter fragments deleted at the $5^{\prime}$ end and treated with $10 \mathrm{nM} \mathrm{PTH} \mathrm{(1-34)} \mathrm{for} 12 \mathrm{~h} \mathrm{(B).} \mathrm{To}$ determine the involvement of $\mathrm{NFKB}$, cells were transiently transfected with $N F_{\kappa} B$ reporter containing four $N F \kappa B$-binding sites $(\mathrm{NF} \kappa \mathrm{B} \times 4)$ or $-1269 /+91$ Osx promoter with $\mathrm{NF} \kappa \mathrm{B}$-binding site deleted $(\Delta \mathrm{NF} \kappa \mathrm{B})$ or mutated $(\mathrm{m} 217 / 214)$ and treated with $10 \mathrm{nM}$ PTH (1-34) for $12 \mathrm{~h}(\mathrm{C})$. Luciferase activities standardized with $\beta$-gal activities were plotted as percentage of the basal activity of the specific construct without PTH treatment. Results from at least three independent experiments were plotted with error bars representing mean \pm S.E.M. Statistical significance were represented by ${ }^{\star} P<0.05$. 
the UMR-106 cells used by Wang et al. are different from the UMR-106-01 clone used in our study, which was derived from the UMR-106-01 cell line first generated by Partridge's group. In any event, the UMR cells used in our study showed the same effect of PTH (1-34) on Osx expression as seen in primary mouse calvaria, and therefore they are more likely to be mimicking effects that would be seen in vivo.

The inhibition of Osx by PTH may be part of the catabolic effects seen in response to continuous exposure to the hormone. Previous reports have shown that prolonged exposure of calvaria-derived osteoblasts to PTH results in decreased osteoblast differentiation with decreased expression of collagen 1a1, bone sialoprotein, and osteocalcin (Xing et al. 2007). Some of these genes could have been suppressed as a result of PTH-mediated Osx inhibition, as both osteocalcin and collagen lal are regulated by Osx. The effect of prolonged PTH exposure on Osx expression in vivo has not been tested; however, intermittent PTH administration to mice with bone fractures showed increased Osx expression in bone marrow-derived mesenchymal stem cells with increased osteoblast differentiation (Kaback et al. 2008). It will be interesting to examine whether continuous and intermittent treatment with PTH has opposite effects on Osx expression in vivo.

Two Osx isoforms of $\sim 46$ and $56 \mathrm{kDa}$ were detected in our studies. The identity of the Osx protein isoforms was further confirmed by transient overexpression of a cDNA encoding Osx protein in UMR cells. Alternative splicing generates three Osx mRNAs resulting in two protein isoforms that are much closer in molecular weight than the two forms that we see in UMR cells and calvaria (Gao et al. 2004, Nishio et al. 2006). It is possible that post-translational modifications may be responsible for the higher molecular weight Osx isoform we observed. For example, Sp1 is extensively glycosylated with O-linked sugars (Jackson \& Tjian 1988) and phosphorylated (Jackson et al. 1990). Osx, as a member of the Sp family, may also be glycosylated and phosphorylated accounting for the multiple molecular weight isoforms seen here; however, more investigations are necessary to understand post-translational modifications of Osx and the significance of these processes in transcriptional regulation.

Runx2 has been shown to transactivate the Osx promoter in chondroprogenitor cells (Nishio et al. 2006). We did not see any loss of Runx2 mRNA in our cells or calvaria following PTH (1-34) treatment for up to $24 \mathrm{~h}$, although a trend toward suppression that was not statistically significant was observed, and PTH (1-34) treatment for $6 \mathrm{~h}$ was clearly capable of stimulating an OSE2 reporter construct that responds to stimulated Runx2; suggesting that within the time of onset of PTH inhibition of Osx, Runx2, which typically acts as an activator, is unlikely to mediate this process. PTH has been reported to deplete around $40 \%$ of Runx2 protein through proteasomal degradation in OB-6 cells (Bellido et al. 2003); however, the effect was transient with full recovery of Runx2 protein by $24 \mathrm{~h}$ with continuous PTH stimulation. We did not evaluate the amount of Runx2 protein in our samples following PTH (1-34) treatment; however, given our results showing no change in Runx2 mRNA and stimulation of Runx2 activity, we think it is unlikely to be a major factor in PTH-mediated inhibition of Osx.

Investigations into the mechanism by which PTH (1-34) inhibits Osx expression in our studies clearly showed a role for cAMP. PTH (1-31), a PTH fragment that specifically stimulates cAMP (Jouishomme et al. 1994), caGs $\alpha$, Fsk, and 8-Br-cAMP all inhibited Osx mRNA levels. PTH (3-34), previously shown not to stimulate cAMP (Erclik \& Mitchell 2002), had no effect on Osx mRNA levels. RpcAMP, a competitive inhibitor of PKA, was able to partially block PTH (1-34) inhibition of Osx, whereas the EPAC-selective stimulator 8CPT-2Me-cAMP (Kang et al. 2003) had no effect. Thus, it seems likely that PKA rather than EPAC may mediate some of the effects of PTH on Osx; however, further studies are required to fully elucidate the signaling pathway between cAMP and Osx gene transcription.

PTH (7-34), which does not activate PTH1R, actually stimulated the Osx mRNA level above basal. This PTH analog can induce internalization of the receptor in some cell types' cell-specific manner (Sneddon et al. 2003, 2004); however, UMR-106-01 cells express NHERF1 that has been shown to inhibit PTH1R internalization (Wheeler et al. 2008). An alternative explanation for the ability of PTH (7-34) to stimulate Osx is that UMR cells express and secrete small amounts of PTHrP (Suda et al. 1996), which can also bind to the PTH1R receptor. Therefore, PTH (7-34) may have competed with endogenously expressed PTHrP for PTH1R occupancy, resulting in a net decrease in PTH1R-basal activity and higher Osx levels. Finally, Osx mRNA levels were stimulated in UMR cells expressing caGq $\alpha$, suggesting that stimulators of PLC/ PKC may positively regulate Osx expression in osteoblasts. PTH (1-34) stimulates PLC activity in UMR106-01 cells but only weakly (Mitchell \& Bansal 1997, Cheung et al. 2005), and therefore the cAMP pathway is dominant resulting in a net decrease in Osx expression. Further studies are required to determine whether PTH analogs reported to stimulate PLC and not adenylyl cyclase (reviewed by Morley et al. 1999) can stimulate Osx levels in either osteoblast cell lines or in calvaria.

Our studies did demonstrate that PTH (1-34) inhibition of Osx is most likely to be at the transcriptional level since it had no effect on Osx mRNA stability and is independent of new protein synthesis in the cells. A similar pattern of direct inhibition of Osx was seen 
in MC3T3 cells with TNF- $\alpha$ (Lu et al. 2006). Using a 1292-bp fragment of the Osx promoter to drive a luciferase reporter, PTH (1-34) was found to inhibit the activity of the promoter with a similar time course as seen for the inhibition of Osx mRNA. The profound inhibition of the luciferase activity seen with longer PTH treatments may be due in part to the loss of autoregulation of the promoter by Osx itself. Although there are several binding sites for PTH-responsive transcription factors, such as Runx2 and CREB, within the longest promoter fragment used in our studies, none of these is likely to mediate PTH inhibition of the promoter activity as deletion constructs without these putative binding sites retained full responsiveness to PTH. Within the PTH-responsive region of the

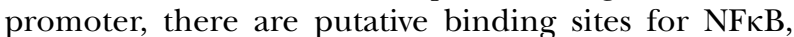
VDR, Dlx-5, NF-Y, and a GC-rich box that binds Sp transcription factors (Lu et al. 2006, Nishio et al. 2006).

$\mathrm{NF} \kappa \mathrm{B}$ can be stimulated by PTH as shown here and by others (Ali et al. 1999), and NFKB has been reported to regulate the proximal Osx promoter ( $\mathrm{Lu}$ et al. 2006). However, mutation or deletion of the $\mathrm{NF} \kappa \mathrm{B}$ site within the promoter construct had no effect on the ability of $\mathrm{PTH}$ to inhibit their activity in our assays, indicating that NFКB is not involved in PTH inhibition of Osx. PTH has been reported to either up-regulate or downregulate vitamin $\mathrm{D}$ receptors depending on the conditions. The only reported effect of vitamin D on Osx showed an increase in Osx mRNA levels in a human osteoblastic cell line, MG-63 cells (Maehata et al. 2006); thus, it is unlikely that the VDR response element in the Osx promoter mediates PTH inhibition of Osx transcription. Dlx-5 is a transcription factor required for the development of a number of calcified tissues, and it has recently been found to mediate BMP-2 induction of Osx (Ulsamer et al. 2008). Stimulation of Dlx-5 mRNA by PTH has been reported, and therefore it is again unlikely to mediate PTH inhibition of Osx.

A GC-rich sequence is within the shortest PTHresponsive region of the Osx promoter tested in our assays. A number of transcription factors belonging to the Sp family including Sp1, Sp3, and Sp7 itself can all bind to such GC-rich elements. Sp1 and Sp3 are ubiquitously expressed members of this family and can combine with other members of the Sp family to have both positive and negative effects on gene transcription (Goto et al. 2006). Further analysis of the response elements within the proximal $70 \mathrm{bp}$ of the Osx promoter will be required to determine whether Sp proteins or other transcription factors are involved in PTH-mediated suppression of Osx transcription.

In summary, we have demonstrated for the first time that PTH down-regulates Osx expression in osteoblasts by a transcriptional mechanism mediated by cAMP signaling. The sites of inhibition within the Osx promoter have been shown to reside within the first $300 \mathrm{bp}$ of the $5^{\prime}$-flanking region of the $o s x 1$ transcription start site. Further studies are required to identify the specific transcriptional repressors that mediate this effect, and studies in vivo are required to determine whether inhibition of Osx by PTH contributes to its catabolic effects of this hormone on bone.

\section{Declaration of interest}

There is no conflict of interest that could be perceived as prejudicing the impartiality of the research reported.

\section{Funding}

This work was supported by a grant from the Canadian Institutes for Health Research (MOP15696).

\section{References}

Ali NN, Gilston V \& Winyard PG 1999 Activation of NF-кB in human osteoblasts by stimulators of bone resorption. FEBS Letters 460 315-320.

Bellido T, Ali AA, Plotkin LI, Fu Q, Gubrij I, Roberson PK, Weinstein RS, O’Brien CA, Manolagas SC \& Jilka RL 2003 Proteasomal degradation of Runx2 shortens parathyroid hormone-induced anti-apoptotic signaling in osteoblasts. A putative explanation for why intermittent administration is needed for bone anabolism. Journal of Biological Chemistry 278 50259-50272.

Bos MP, van der Meer JM, Feyen JH \& Herrmann-Erlee MP 1996 Expression of the parathyroid hormone receptor and correlation with other osteoblastic parameters in fetal rat osteoblasts. Calcified Tissue International 58 95-100.

Cao Y, Jia SF, Chakravarty G, de Crombrugghe B \& Kleinerman ES 2008 The osterix transcription factor down-regulates interleukin-1 alpha expression in mouse osteosarcoma cells. Molecular Cancer Research 6 119-126.

Celil AB \& Campbell PG 2005 BMP-2 and insulin-like growth factor-I mediate osterix (Osx) expression in human mesenchymal stem cells via the MAPK and protein kinase D signaling pathways. Journal of Biological Chemistry 280 31353-31359.

Cheung R, Erclik MS \& Mitchell J 2005 Increased expression of $\mathrm{G}_{11} \alpha$ in osteoblastic cells enhances parathyroid hormone activation of phospholipase $\mathrm{C}$ and AP-1 regulation of matrix metalloproteinase13 mRNA. Journal of Cellular Physiology 204 336-343.

Ducy P \& Karsenty G 1995 Two distinct osteoblast-specific cis-acting elements control expression of a mouse osteocalcin gene. Molecular and Cellular Biology 15 1858-1869.

Ducy P, Zhang R, Geoffroy V, Ridall AL \& Karsenty G 1997 Osf2/Cbfal: a transcriptional activator of osteoblast differentiation. Cell $\mathbf{8 9}$ $747-754$.

Erclik MS \& Mitchell J 2002 The role of protein kinase C-delta in PTH stimulation of IGF-binding protein-5 mRNA in UMR-106-01 cells. American Journal of Physiology. Endocrinology and Metabolism 282 E534-E541.

Forrest SM, Ng KW, Findlay DM, Michelangeli VP, Livesey SA, Partridge NC, Zajac JD \& Martin TJ 1985 Characterization of an osteoblast-like clonal cell line which responds to both parathyroid hormone and calcitonin. Calcified Tissue International $3751-56$ 
Frolik CA, Black EC, Cain RL, Satterwhite JH, Brown-Augsburger PL, Sato M \& Hock JM 2003 Anabolic and catabolic bone effects of human parathyroid hormone (1-34) are predicted by duration of hormone exposure. Bone 33 372-379.

Gao Y, Jheon A, Nourkeyhani H, Kobayashi H \& Ganss B 2004 Molecular cloning, structure, expression, and chromosomal localization of the human Osterix (SP7) gene. Gene 341 101-110.

Goto T, Matsui Y, Fernandes RJ, Hanson DA, Kubo T, Yukata K, Michigami T, Komori T, Fujita T, Yang L et al. 2006 Sp1 family of transcription factors regulates the human alpha2 (XI) collagen gene (COL11A2) in Saos-2 osteoblastic cells. Journal of Bone and Mineral Research 21 661-673.

van der Horst G, Farih-Sips H, Löwik CW \& Karperien M 2005 Multiple mechanisms are involved in inhibition of osteoblast differentiation by PTHrP and PTH in KS483 Cells. Journal of Bone and Mineral Research 20 2233-2244.

Jackson SP \& Tjian R 1988 O-glycosylation of eukaryotic transcription factors: implications for mechanisms of transcriptional regulation. Cell 55 125-133.

Jackson SP, MacDonald JJ, Lees-Miller S \& Tjian R 1990 GC box binding induces phosphorylation of Sp1 by a DNA-dependent protein kinase. Cell 63 155-165.

Jouishomme H, Whitfield JF, Gagnon L, Maclean S, Isaacs R, Chakravarthy B, Durkin J, Neugebauer W, Willick G \& Rixon RH 1994 Further definition of the protein kinase $\mathrm{C}$ activation domain of the parathyroid hormone. Journal of Bone and Mineral Research $\mathbf{9}$ 943-949.

Kaback LA, Soung DY, Naik A, Geneau G, Schwarz EM, Rosier RN, O'Keefe RJ \& Drissi H 2008 Teriparatide (1-34 human PTH) regulation of osterix during fracture repair. Journal of Cellular Biochemistry 105 219-226.

Kang G, Joseph JW, Chepurny OG, Monaco M, Wheeler MB, Bos JL, Schwede F, Genieser HG \& Holz GG 2003 EPAC-selective cAMP analog 8-pCPT-2'-O-Me-cAMP as a stimulus for $\mathrm{Ca}^{2+}$-induced $\mathrm{Ca}^{2+}$ release and exocytosis in pancreatic beta-cells. Journal of Biological Chemistry 278 8279-8285.

Kim BG, Kim HJ, Park HJ, Kim YJ, Yoon WJ, Lee SJ, Ryoo HM \& Cho JY 2006 Runx2 phosphorylation induced by fibroblast growth factor2/protein kinase C pathways. Proteomics 6 1166-1174.

Komori T, Yagi H, Nomura S, Yamaguchi A, Sasaki K, Deguchi K, Shimizu Y, Bronson RT, Gao YH, Inada M et al. 1997 Targeted disruption of Cbfal results in a complete lack of bone formation owing to maturational arrest of osteoblasts. Cell $\mathbf{8 9}$ $755-764$.

Kream BE, Rowe DW, Gworek SC \& Raisz LG 1980 Parathyroid hormone alters collagen synthesis and procollagen mRNA levels in fetal rat calvaria. PNAS 77 5654-5658.

Lai LP, DaSilva KA \& Mitchell J 2005 Regulation of Indian hedgehog mRNA levels in chondrocytic cells by ERK1/2 and p38 mitogen-activated protein kinases. Journal of Cellular Physiology 203 177-185.

Lee SK \& Lorenzo JA 1999 Parathyroid hormone stimulates TRANCE and inhibits osteoprotegerin messenger ribonucleic acid expression in murine bone marrow cultures: correlation with osteoclast-like cell formation. Endocrinology 140 3552-3561.

Lee MH, Kwon TG, Park HS, Wozney JM \& Ryoo HM 2003 BMP-2induced Osterix expression is mediated by Dlx 5 but is independent of Runx2. Biochemical and Biophysical Research Communications 309 689-694.

Lu X, Gilbert L, He X, Rubin J \& Nanes MS 2006 Transcriptional regulation of the osterix ( $\mathrm{Osx}, \mathrm{Sp} 7)$ promoter by tumor necrosis factor identifies disparate effects of mitogen-activated protein kinase and NF- $\kappa \mathrm{B}$ pathways. Journal of Biological Chemistry 281 6297-6306.

Maehata Y, Takamizawa S, Ozawa S, Kato Y, Sato S, Kubota E \& Hata R 2006 Both direct and collagen-mediated signals are required for active vitamin $\mathrm{D}_{3}$-elicited differentiation of human osteoblastic cells: roles of osterix, an osteoblast-related transcription factor. Matrix Biology 25 47-58.

Milona MA, Gough JE \& Edgar AJ 2003 Expression of alternatively spliced isoforms of human $\mathrm{Sp} 7$ in osteoblast-like cells. $B M C$ Genomics 443.

Mitchell J \& Bansal A 1997 Dexamethasone increases $\mathrm{G} \alpha_{\mathrm{q}-11}$ expression and hormone stimulated phospholipase $\mathrm{C}$ activity in UMR-106-01 cells. American Journal of Physiology 27 E528-E535.

Morley P, Whitfield JF \& Willick GE 1999 Design and applications of parathyroid hormone analogues. Current Medicinal Chemistry 6 1095-1106.

Nakashima K, Zhou X, Kunkel G, Zhang Z, Deng JM, Behringer RR \& de Crombrugghe B 2002 The novel zinc finger-containing transcription factor osterix is required for osteoblast differentiation and bone formation. Cell 108 17-29.

Nishio Y, Dong Y, Paris M, O’Keefe RJ, Schwarz EM \& Drissi H 2006 Runx2-mediated regulation of the zinc finger Osterix/Sp7 gene. Gene 372 62-70.

Noda M \& Rodan GA 1989 Transcriptional regulation of osteopontin production in rat osteoblast-like cells by parathyroid hormone. Journal of Cellular Biology 108 713-718.

Qin L, Qiu P, Wang L, Li X, Swarthout JT, Soteropoulos P, Tolias P \& Partridge NC 2003 Gene expression profiles and transcription factors involved in parathyroid hormone signaling in osteoblasts revealed by microarray and bioinformatics. Journal of Biological Chemistry 278 19723-19731.

Selvamurugan N, Pulumati MR, Tyson DR \& Partridge NC 2000 Parathyroid hormone regulation of the rat collagenase-3 promoter by protein kinase A-dependent transactivation of core binding factor alpha1. Journal of Biological Chemistry $\mathbf{2 7 5}$ $5037-5042$.

Selvamurugan N, Shimizu E, Lee M, Liu T, Li H \& Partridge NC 2009 Identification and characterization of Runx2 phosphorylation sites involved in matrix metalloproteinase-13 promoter activation. FEBS Letters 583 1141-1146.

Sneddon WB, Syme CA, Bisello A, Magyar CE, Rochdi MD, Parent JL, Weinman EJ, Abou-Samra AB \& Friedman PA 2003 Activationindependent parathyroid hormone receptor internalization is regulated by NHERF1 (EBP50). Journal of Biological Chemistry 278 $43787-43796$.

Sneddon WB, Magyar CE, Willick GE, Syme CA, Galbiati F, Bisello A \& Friedman PA 2004 Ligand-selective dissociation of activation and internalization of the parathyroid hormone (PTH) receptor: conditional efficacy of PTH peptide fragments. Endocrinology 145 2815-2823.

Suda N, Gillespie MT, Traianedes K, Zhou H, Ho PW, Hards DK, Allan EH, Martin TJ \& Moseley JM 1996 Expression of parathyroid hormone-related protein in cells of osteoblast lineage. Journal of Cellular Physiology 166 94-104.

Termine JD, Kleinman HK, Whitson SW, Conn KM, McGarvey ML \& Martin GR 1981 Osteonectin, a bone-specific protein linking mineral to collagen. Cell 26 99-105.

Tominaga H, Maeda S, Miyoshi H, Miyazono K, Komiya S \& Imamura T 2009 Expression of osterix inhibits bone morphogenetic proteininduced chondrogenic differentiation of mesenchymal progenitor cells. Journal of Bone and Mineral Metabolism 27 36-45.

Ulsamer A, Ortuño MJ, Ruiz S, Susperregui AR, Osses N, Rosa JL \& Ventura F 2008 BMP-2 induces Osterix expression through up-regulation of Dlx5 and its phosphorylation by p38. Journal of Biological Chemistry 283 3816-3826.

Wang BL, Dai CL, Quan JX, Zhu ZF, Zheng F, Zhang HX, Guo SY, Guo G, Zhang JY \& Qiu MC 2006a Parathyroid hormone regulates osterix and Runx2 mRNA expression predominantly through protein kinase A signaling in osteoblast-like cells. Journal of Endocrinological Investigation 29 101-108.

Wang X, Kua HY, Hu Y, Guo K, Zeng Q, Wu Q, Ng HH, Karsenty G, de Crombrugghe B, Yeh J et al. $2006 b$ p53 functions as a negative 
regulator of osteoblastogenesis, osteoblast-dependent osteoclastogenesis, and bone remodeling. Journal of Cellular Biology 172 $115-125$.

Wheeler D, Garrido JL, Bisello A, Kim YK, Friedman PA \& Romero G 2008 Regulation of parathyroid hormone type 1 receptor dynamics, traffic, and signaling by the $\mathrm{Na}^{+} / \mathrm{H}^{+}$exchanger regulatory factor- 1 in rat osteosarcoma ROS 17/2.8 cells. Molecular Endocrinology 22 $1163-1170$.

Xing W, Singgih A, Kapoor A, Alarcon CM, Baylink DJ \& Mohan S 2007 Nuclear factor-E2-related factor-1 mediates ascorbic acid induction of osterix expression via interaction with antioxidantresponsive element in bone cells. Journal of Biological Chemistry 282 22052-22061.
Zambetti GP, Horwitz EM \& Schipani E 2006 Skeletons in the p53 tumor suppressor closet: genetic evidence that p53 blocks bone differentiation and development. Journal of Cellular Biology 172 795-797.

Zhang C, Cho K, Huang Y, Lyons JP, Zhou X, Sinha K, McCrea PD \& de Crombrugghe B 2008 Inhibition of Wnt signaling by the osteoblast-specific transcription factor Osterix. PNAS 105 6936-6941.

Received in final form 7 May 2009

Accepted 8 June 2009

Made available online as an Accepted Preprint 8 June 2009 